Article

\title{
Influencers With Intellectual Disability in Digital Society: An Opportunity to Advance in Social Inclusion
}

\author{
Mónica Bonilla-del-Río ${ }^{1}$, Bárbara Castillo-Abdul ${ }^{2,3}$, Rosa García-Ruiz ${ }^{4,5, *}$, and Alejandro Rodríguez-Martín ${ }^{6}$ \\ ${ }^{1}$ Department of Philology, University of Huelva, Spain \\ 2 Department of Communication Sciences and Sociology, Rey Juan Carlos University, Spain \\ ${ }^{3}$ ESAI Business School, Espiritu Santo University, Ecuador \\ ${ }^{4}$ Department of Education, Universidad de Cantabria, Spain \\ ${ }^{5}$ Nebrija University, Spain \\ ${ }^{6}$ Department of Education Sciences, University of Oviedo, Spain \\ * Corresponding author (rosa.garcia@unican.es)
}

Submitted: 30 July 2021 | Accepted: 13 September 2021 | Published: 24 February 2022

\begin{abstract}
Social networks are appointed as an opportunity to socially normalize disability, as demonstrated by the growing number of influencers with a disability who are followed by millions of users. Likewise, intellectual disability has its place in the networks, with special relevance among influencers with Down syndrome. In this study, a content analysis of 10 accounts of influencers with Down syndrome from seven different countries was performed. Images, videos, comments, and other interactions with their followers were analyzed. The preliminary results described the influencer profiles, the type of content posted, and their relationship with sponsoring brands. These results indicate that social networks allow them to make their interests visible, take part in the digital environment, and interact with their audience, being a positive influence that promotes respect for diversity. These platforms are positioned as powerful tools for the construction and dissemination of inclusive values and the empowerment of disabled people, minimizing controversial questions such as the instrumentalization of the disability and its association with clichés. With all the analyzed results, it is possible to evidence that Instagram can be considered a privileged network that could be utilized for the eradication of barriers and to ease the inclusion of people with intellectual disabilities in the public sphere. The conclusions are relevant for the scientific community given that they will allow us to achieve social inclusion, thanks to the impact of the posts from the influencers with disability.
\end{abstract}

\section{Keywords}

digital inclusion; disability; down syndrome; influencer; Instagram; social inclusion; social networks

\section{Issue}

This article is part of the issue "New Narratives for New Consumers: Influencers and the Millennial and Centennial Generations" edited by Luis M. Romero-Rodríguez (Rey Juan Carlos University), Santiago Tejedor (Autonomous University of Barcelona), and Inmaculada Berlanga (International University of La Rioja).

(C) 2022 by the author(s); licensee Cogitatio (Lisbon, Portugal). This article is licensed under a Creative Commons Attribution 4.0 International License (CC BY).

\section{Introduction}

Social networks (SNs) offer new ways of communicating on the internet and allow interactive activities through the use of different formats for the diffusion and exchange of audiovisual content. Facebook, Twitter, YouTube, WhatsApp, Instagram, and Tiktok are the SNs with the most significant number of followers worldwide.
Instagram is the SN with the most considerable growth in the number of users and visits, obtaining 1,221 million active users worldwide, implying an increase of $22.1 \%$ with respect to the previous year (Kemp, 2020). It is positioned as the fifth $\mathrm{SN}$ with the greatest number of users, whose profile is eminently young, and female to a greater degree (Caldeira, 2021). However, the changes added recently, such as filters, reels, and the widespread 
growth of the shopping option have improved its impact. This study aims to identify the practices and interactions of influencers with Down syndrome on Instagram, starting with the content analysis of their profiles and interactions with their audience. The study includes an important analysis of a little-studied reality, as similar studies are not expected. Suggestions are provided on how to improve the visibility of intellectual disability through SNs, and actions are suggested at the social, educational, and political levels to take advantage of the influencers' impact and improve the inclusion of this collective.

\section{Social Networks, Disability, and the Role of Influencers}

The SNs have implied a significant advance in the improvement of the quality of life of people with disability, easing their access to education, enriching their leisure time, and improving their relationships with others. However, a challenge still exists in achieving the full participation of this collective in a society that is becoming more technology-centered, as digital inclusion is influenced by multiple factors and the diversity of experiences (Tsatsou, 2019, 2020). The use of these media by disabled youth is a recurring worry in the scientific literature, mainly from the start of this century (Caton \& Chapman, 2016), and it is still a challenge, as shown by the analysis of themes such as risks and vulnerabilities, opportunities, sexuality, identity, barriers, and supports (Borgström et al., 2019). The work by Bayor et al. (2018) indicates that this collective has different interests as a function of the SN in which they participate, namely, they use YouTube to entertain themselves, Facebook to connect with family members, and Snapchat and Instagram to interact with strangers in a leisurely manner.

Despite the increase in the use of SNs by individuals with disabilities, shifting from being simple users to protagonists, and therefore improving their opportunities of social participation, in some cases, these platforms still have barriers concerning accessibility and usability, which translates into a digital divide that is difficult to overcome (Werner \& Shpigelman, 2019). In this sense, in agreement with Saz-Torralba et al. (2011), resources that should initially ease the access to information and social interaction create inequalities, so that e-inclusion is set as a fundamental element in current societies, which must wager on the promotion of solutions at the technical level, and the design and development of tailored devices that are linked to the principle of universal accessibility or the universal design for learning (UDL).

Indeed, this sense of universality and diversity has accompanied the long and intense road towards conceptualization in the area of disability. Disabled individuals and their social fabric have constantly demanded laws, procedures, and concepts that are aware of differences. Tradition in most countries is the most important influence of the medical-clinical focus (Shume, 2020).
Faced with the hegemony which impregnates language and the professional practice of many collectives, there is a social model of disability with an emancipating ideology that tries to project a positive image of disability, placing value on the competencies as opposed to the needs; the opportunities as opposed to the difficulties, and overall, the importance of the context as opposed to individual limitations. For this, we find the International Classification Functioning, Disability, and Health (ICF), which comprises the current conceptual framework of disability (World Health Organization, 2001), for a new understanding of functioning, disability, and health. This universal classification system establishes a standardized framework and language that encompass three essential components: body/structure functions, activity, and participation integrated under the terms "functioning" and "disability," which depend on the health conditions and their interaction with contextual factors.

The ICF is a universal classification benchmark and currently serves as the framework for the United Nations and other specialized agencies, such as the UN Statistics Division, UNESCO, and the International Labour Organization. Also, the ICF has a close relationship with the demands from the Independent Living Movement (Carbonell, 2019) and is also the basis for the Convention on the Rights of Persons with Disabilities (United Nations, 2006).

Due to this, the term "disability" is used in the present work, although the focus of the research and the intention of its dissemination is entirely inclusive as a contribution towards the Sustainable Development Goals (SDG). Sustainability is a significant global challenge, which the SDG associate with training and social participation (UNESCO, 2015a). Inclusion and sustainability are closely related, and the fundamental principles of social equity and equality are interdependent and fundamental for sustainable development. The main objective is to broaden the opportunities for everyone and to guarantee the social presence, participation, and progress of every individual, especially those with a disability.

Within the values defined by Booth and Ainscow (2015), from an inclusive perspective, the value of sustainability is essential, as inclusion is defined as belonging, being valued, and obtaining the necessary support for progress to be made (Goodall, 2020). Therefore, the processes of educational inclusion are associated with the achievement of the 17 SDG (UNESCO, 2015b). The 2030 Agenda for Sustainable Development is an instrument that underlines the mutual dependency that exists between the inclusion processes, inclusive training, social participation, and sustainable development (UNESCO, 2015c).

\subsection{Risk and Benefits of Use of Social Networks by Disabled Youth}

Being a SN user and taking advantage of their opportunities implies being exposed to content that is risky, 
especially among the youth, so it is necessary, according to Vissenberg and d'Haenens (2020), to create a safe environment that favors the use of communicational and proactive coping strategies, in which resilience plays a fundamental role. The studies by Sallafranque-St-Louis and Normand (2017) or Chiner et al. (2017) show evidence about how the youth with an intellectual disability or autism experienced distressing situations on the use of the internet and needed support for overcoming them (friends, family, professionals, etc.). Therefore, it is necessary to guarantee the safe and positive use of the internet with special emphasis on this collective agreement with these experts on the crucial role of education in this area. Likewise, Setchell et al. (2020) pointed out that the use and access of technology by disabled individuals can be harmful, create greater exclusion, and broaden the digital divide if they are not adapted or are not accessible. For example, if we are trying to promote the use of SNs, but the user does not have many friends for this (White \& Forrester-Jones, 2019), this can have a negative effect.

At the same time, SNs offer individuals with disabilities the opportunity to participate in a digital environment, allowing them to exchange supports (Suriá, 2017), increase their social participation (Raghavendra et al., 2015), and therefore, their social-educational inclusion (Kim \& Quian, 2019; Román \& Rodríguez-Martín, 2019), at the same time that they favor their visibility. Along the same line, Chadwick et al. (2016) suggest the need to improve the online access of this collective to take greater advantage of their benefits, given that, according to Ramstem et al. (2018), despite the use of the ICT by these youth, they do so to a lesser degree than their peers, and with a different pattern of use (Alfredsson et al., 2019), being dependent on the support from their environment (Borgström et al., 2019). Research studies such as those by Kim and Quian (2019) have shown that the use of SNs by individuals with an intellectual disability provides benefits, such as the improvement in social capital, self-confidence, and a positive image of oneself. They also point out that SNs are tools that favor social inclusion but require the efficient support of one's surroundings to guarantee their safe use. Other networks such as YouTube are used by the youth to build their own identity, presenting and expressing themselves, and searching the identification of their users with their own identity (Pérez-Torres et al., 2018).

\subsection{Social Networks to Show Disability}

More and more individuals with a disability are utilizing SNs as a tool to make their collective visible. Individuals with a disability make use of different SNs such as YouTube, Instagram, or their own blogs to make themselves known, to show their identity (Borgström et al., 2019), and to have an influence on their followers, using them as a loudspeaker to communicate multiple messages, and not only with a commercial aim. This opportunity to visualize their own identity allows them to overcome tags or clichés such as "learning disability," emphasizing other aspects of their identity (Borgström et al., 2019), achieving greater participation in the digital sphere, and therefore favoring their social inclusion, aspects which will guide the present research study.

In this way, Instagram has established itself as a platform that favors the development of identity and the self-expression of youth with disabilities, facilitating the construction of community, both online and in their social surroundings (Tollan, 2020). Likewise, just as with other SNs, Instagram allows the self-representation of individuals with disabilities through different sociotechnical possibilities, which lead to novel behaviors, the revelation of information about oneself, and new interactions between individuals, which up to now were unthinkable. Self-representation on Instagram can be analyzed starting with the theory by Goffman (1959) about selfrepresentation which sustains that people play social roles in their interactions with others, being able to be more or less aware or sensitive to how they play this role, which is critically important when dealing with individuals who belong to a collective that can be marginalized or stigmatized, such as the case of individuals with a disability or LGTBI individuals (Birnholtz \& Macapagal, 2021).

The possibilities offered by SNs for individuals with disabilities to define their profiles and select how they want to show themselves in the digital sphere also allow for the overcoming of the instrumentalization of disability which has derived into a social image (Ledesma, 2008; Vidal-García, 2021; Viñarás-Abad et al., 2021) which does not always correspond to the reality shown by influencers in SNs.

\subsection{The Role of Influencers in the Public Sphere}

The term influencer is not new and did not appear along with the appearance of SNs since, according to Castelló-Martínez (2016), influencers in the 1960s were defined as famous people or celebrities who influenced consumers regarding purchasing recommendations. Presently, they are defined as individuals with a high number of followers and a high level of engagement, meaning that they create loyalty in their followers through the creation of solid relationships.

Influencers are defined by Marketing Directo (2020) as individuals through which SNs generate information about brands, products, or services, and interact with their followers by sharing ideas and opinions. According to Alassani and Göretz (2019), influencers can be classified as a function of the number of followers into the following categories: nano-influencers, micro-influencers, macro-influencers, and mega-influencers. The number of followers reached by micro-influencers, who will be the object of study in the present work, along with the macroinfluencers, lies between four and five figures. On their part, the macro-influencers have a number of followers that reach six to seven digits, which results in a decrease in the level of commitment of $5-25 \%$ in this sector. 
As for the brands, the marketing of influence through digital platforms is established as one of the most efficient strategies of communication and marketing, increasing the notoriety of the brand, creating commercial opportunities, and client loyalty (del-Pino-Romero \& Castelló-Martínez, 2017). In this sense, in agreement with Augure (2015), the most frequent situations in which brands resort to relationships with influencers are the creation and distribution of content or the launching of products. On their part, the main motivation of the influencers for collaborating with different brands is to increase their reach or audience, create the brand image, obtain advantages (discounts or gifts), economic gain, or live new experiences.

\section{Method}

For this, a study was conducted comprising of two differentiated phases.

\subsection{Sample}

The sample was composed of 10 accounts of influencers with Down syndrome (Table 1). The influencer accounts were obtained through the Social Blade website by selecting those that met the following criteria:

- Accounts managed directly by individuals with Down syndrome and not by families or associations.

- The number of followers.

- Belonged to the micro-influencers category.

- The nationality of the Instagrammers, who belonged to seven different countries.

- Published in alphabetic languages and not in ideographic languages (i.e., Chinese or Japanese).

From the accounts that met these requirements, a sample of 10 accounts was selected, which were diverse in their geographical origin (America, Europe, and Oceania),

Table 1. Sample characteristics

\begin{tabular}{|c|c|c|c|c|c|}
\hline Name & Username & Followers & Country & $\begin{array}{l}\text { Category and/or } \\
\text { Instagram bio }\end{array}$ & Link \\
\hline Madeline Stuart & @madelinesmodelling & $356 \mathrm{~K}$ & Australia & $\begin{array}{l}\text { Public figure/super } \\
\text { model with Down } \\
\text { syndrom }\end{array}$ & https://bit.ly/3qz8lg2 \\
\hline Gabriel Bernardes & @downlicia_oficial & $339 \mathrm{~K}$ & Brazil & $\begin{array}{l}\text { Entrepreneur/ } \\
\text { ambassador: @bis } \\
\text { and @Formula } \\
\text { NaturalOficial }\end{array}$ & https://bit.ly/3qyk0vo \\
\hline Chelsea Werner & @showtimewerner & $193 \mathrm{~K}$ & USA & $\begin{array}{l}\text { 2X World champion } \\
\text { gymnast, 4X Special } \\
\text { Olympics champion } \\
\text { @womwnbest } \\
\text { athlete }\end{array}$ & https://bit.ly/3DTP4wf \\
\hline Kate Grant & @kategrantmodel & $43.7 \mathrm{~K}$ & Ireland & $\begin{array}{l}\text { 1st model in NI with } \\
\text { Down's syndrome }\end{array}$ & https://bit.ly/3zHY9pn \\
\hline Sofía Jirau & @sofiajirau & $121 \mathrm{~K}$ & $\begin{array}{l}\text { Puerto } \\
\text { Rico }\end{array}$ & $\begin{array}{l}\text { Model/professional } \\
\text { model }\end{array}$ & https://bit.ly/3qzvrTV \\
\hline Cacai Bauer & @cacaibauer & $369 \mathrm{~K}$ & Brazil & $\begin{array}{l}\text { Digital creator/ } \\
\text { 1st digital inf. with } \\
\text { Down syndrome. } \\
\text { Model, actress, } \\
\text { activist, Ativa } 21 \\
\text { ambassador }\end{array}$ & https://bit.ly/3AjxgJ9 \\
\hline Juliana K. Vieira & @juju.kav & $70.6 \mathrm{~K}$ & Brazil & $\begin{array}{l}\text { Personal blog/ } \\
\text { YouTuber }\end{array}$ & https://bit.ly/3jquBql \\
\hline María José Paiz & @segunmajo & $37 \mathrm{~K}$ & Panama & Blogger & https://bit.ly/3tl1yYQ \\
\hline Patricia Fuentes & @patrifashion & $102 \mathrm{~K}$ & Spain & Public figure & https://bit.ly/3DHgzc6 \\
\hline Christopher González & @chrisinlimites & $23 \mathrm{~K}$ & $\begin{array}{l}\text { Puerto } \\
\text { Rico }\end{array}$ & $\begin{array}{l}\text { Entrepreneur, } \\
\text { motivational } \\
\text { speaker, and chef }\end{array}$ & https://bit.ly/2UJwc0x \\
\hline
\end{tabular}


major languages (English, Portuguese, and Spanish), and sex (most of the accounts belong to women, and this was reflected in the sample selected).

From the accounts selected, the last 20 posts shared between May and June 2021 were analyzed. The procedure followed for this is detailed in Section 3.2.

\subsection{Measurements}

In first place, a content analysis technique was utilized from a quantitative approach, starting with the variables developed in other research studies and which we have adapted to our object of study. In this manner, the following categories and their corresponding indicators are established to quantify the interactions produced in the selected accounts, divided into two types of variables: nominal and scale.

\subsubsection{Nominal}

Among the nominal variables, the type of format (González-Romo \& Iriarte-Aguirre, 2020; Romero-Coves et al., 2020) is shown through indicators about the type of publication on Instagram (video, gif, photograph, reel, IGTV, or carousel).

Another variable is the type of content (GonzalezRomo \& Iriarte-Aguirre, 2020) based on indicators on the publication themes. This variable, given that it had very diverse values that impeded a quantitative analysis was re-codified to classify, in the cases in which the theme was clear and unambiguous, into one of five options. These have been selected according to the characteristics of the profiles of the influencers analysed and in line with McRoberts et al. (2016), Romero-Coves et al.. (2020), González-Romo and Iriarte-Aguirre, (2020), and Villena-Alarcón and Fernández-Torres, (2020). In this way, the following dimensions and categories have been established to analyze the contents of the profiles of different influencers: a) interaction with the audience; b) beauty, fashion, and health; c) inclusion, acceptance, and awareness about Down syndrome; d) lifestyleparties, celebrations, and leisure; e) gastronomy. This allowed us to classify a total of 96 posts, $48 \%$ of the sample, permitting a statistical analysis of these cases. The themes from the rest could not be analyzed given that the themes overlapped (for example, lifestyle and inclusion in many cases) or given that they belonged to isolated categories (for example, a joke is shared on one occasion).

Finally, among the nominal variables is the presence of brands or sponsors (González-Romo \& Iriarte-Aguirre, 2020; Smith et al., 2012) through indicators such as the presence of sponsored posts.

\subsubsection{Scale}

Among the scale variables is the degree of engagement between users and Instagramers (González-
Romo \& Iriarte-Aguirre, 2020; Villena-Alarcón \& Fernández-Torres, 2020), whose indicators are the number of followers, as well as the interactions allowed by Instagram in each post: positive and negative comments, likes, and views (in the case of videos, likes are not an option), as well as the sum of the positive interactions (likes, more positive comments).

In the second phase, and from a qualitative approach, the publications with more significant positive interactions were analyzed (sum of likes and positive comments) of each of the profiles. For this, starting with Romero-Coves et al. (2020) and Villena-Alarcón and Fernández-Torres (2020), the following variables were established: a) type of content, starting with the following characteristics extracted from the quantitative analysis and the biographical information of the profiles themselves-1) beauty, fashion, and health; 2) entrepreneurship and gastronomy; 3) content creators; b) Format of the post; c) presence in SNspresence or absence of the influencer in the post and type of presence (individual, as a couple, secondary, others); d) hashtags-Use of generic hashtags and/or related with disability.

\section{Results}

\subsection{Quantitative Analysis}

The results obtained from the statistical analysis were analyzed with the SPSS v.25 software. The descriptive study of the variables allowed us to observe that the account and posts analyzed corresponded to the category of micro-influencer, with a high number of likes, views, and positive interactions obtained (Table 2). It should be pointed out, nevertheless, that although the mean values were high, the standard deviations were high as well, thereby showing the great diversity between the accounts. This is especially derived from the number of followers of each account, which varied between 23,000 and 370,000 , which has a strong influence on the rest of the variables. On the other hand, the number of negative interactions, in the shape of negative comments, was almost inexistent, and only one post had two negative comments, and another obtained only one negative comment, so that these values were considered marginal, and it was observed that the interaction was generally positive.

Also, it was observed that from the total number of accounts, $30 \%$ did not have a presence beyond Instagram, 20\% also had a presence on YouTube, and the other $5 \%$ had a greater presence in other networks: one of them had a presence in a blog, Facebook, Instagram, and YouTube; another also had a blog, Facebook, and Instagram; another in email, YouTube, and TikTok, aside from Instagram; and the last was also on YouTube and Facebook.

As shown in Table 3, the types of publications in these accounts were overall photographs $-29.5 \%$ of the total- 
Table 2. Degree of commitment between users and Instagrammers.

\begin{tabular}{lccrr}
\hline & Mean & SD & Minimum & Maximum \\
\hline Number of followers & 165,240 & $132,943.33$ & 23,000 & 370,000 \\
Likes & $8,868.91$ & $43,312.52$ & 93 & 516,173 \\
Views & 20,538 & $30,278.60$ & 1,236 & 118,531 \\
Positive interactions & $9,027.96$ & $43,677.46$ & 100 & 520,523 \\
\hline
\end{tabular}

and reels -in $29 \%$ of the accounts. Lastly, it was observed that more than half of the publications had a presence of sponsors (69.5\%), a sign of the frequent collaboration of these accounts with other businesses.

\subsubsection{Inferential Analysis}

A statistically significant and positive correlation was observed, with a large size effect, between the number of views and the number of followers $(r(34)=.71$, $p<.001)$. Thus, the greater number of followers the greater number of views, which is evident due to the weight that the number of followers could have on the rest of the interactions. Nevertheless, and perhaps surprisingly, this variable did not have a significant effect on the number of likes and comments.

No differences were observed from the presence or absence of sponsors, neither to aspects related to the number of views of the videos and IGTV $(t(34)=-.679$, $p=.50)$, the number of likes ( $\mathrm{t}(162)=-1.051, p=.29)$, the number of positive comments $(\mathrm{t}(198)=-.757$, $p=.45)$, nor the total number of positive interactions $(\mathrm{t}(162)=-1.05, p=.29)$.

On the other hand, a positive and statistically significant correlation with a large size effect was observed between the number of likes and the number of positive comments $(r(162)=.94, p<.001)$. This result is coherent given that a post that awakens positive emotions in the shape of likes will also likely receive positive comments and vice-versa. At the same time, as expected, the total number of positive interactions was correlated in a positive and significant manner, and with a large size effect, with the number of likes $(r(162)=1.00, p<.001]$ and

Table 3. Type of format of the posts.

\begin{tabular}{lc}
\hline Type of post & Percentage \\
\hline Photograph & 29.5 \\
Reel & 29 \\
Carousel & 23 \\
Gif & 2 \\
IGTV & 9.5 \\
Video & 6.5 \\
Other & .5 \\
\hline
\end{tabular}

the number of positive comments $(r(162)=.95, p<.001)$. Lastly, this was the same between the number of positive comments and the number of views of the posts in the shape of video or IGTV $(r(162)=.60, p<.001)$.

The type of publication did not seem to have a significant influence on the number of likes $(F(160,3)=1.35$, $p=.25)$ or positive interactions $(F(160,33)=1.36, p=.25)$, although it was observed that the type of post did have an influence on the number of positive comments as a general trend $(F(193,6)=1.81, p=.098)$. Likewise, differences were observed between the number of followers and the presence in other networks $(F(193,6)=14.26$, $p<.001)$. However, the post hoc test did not show a clear trend-for example, that more networks mean more followers-and the small number of cases forces us to consider this test with caution, given that the differences in the number of followers were very notable, and could have had an influence, as previously mentioned.

A trending difference was found between the type of publication and the presence of sponsors (see Table 4; $\left.X^{2}(6,200)=10.95, p=.09, C=.22\right]$, in that we wanted to analyze if having a sponsor or not had an influence on the type of publication. A greater sponsor presence was observed in the carousel posts, which could indicate that this type of post offered a greater richness or a more interesting platform for the promotion of products. This coincides with Social Insider data (Chaves, 2020) which argued that the carousel was the type of publication with greater engagement. However, this could not be verified with an ANOVA test, as no significant differences were found in the engagement as a function of type of post.

Lastly, the publication theme was only relevant with respect to the presence of sponsors $(F(90,5)=5.032$,

Table 4. Presence of brands or sponsors.

\begin{tabular}{lccccc}
\hline & $\begin{array}{r}\text { Presence of } \\
\text { Type of post }\end{array}$ & & & & \\
& Sponsor (\%) & $\chi^{2}$ & $p$ & $c$ & \\
\hline Video & Yes & No & 10.95 & .090 & .22 \\
Gif & 4.9 & 7.2 & & & \\
Photograph & 0 & 2.9 & & & \\
Reel & 29.5 & 29.5 & & & \\
IGTV & 23 & 31.7 & & & \\
Carousel & 6.6 & 10.8 & & & \\
Other & 36.1 & 17.3 & & & \\
\hline
\end{tabular}


$p<.001$ ), which was superior in the fashion, beauty, or health posts where product sponsorship is usually frequent.

\subsection{Qualitative Analysis}

The qualitative analysis performed concerning the content published highlights the important presence of women influencers as compared to men and the privileged space of fashion and gastronomy as important spheres in which to become socially visible. Other accounts were also notable, where the users disseminated their everyday actions with closeness and a certain naturalness.

In every publication analyzed, the influencer seeks to create engagement by mentioning the external accounts or questions from users, interactions, or user responses. Another common feature between these accounts was the presence of the Instagrammer, who appeared in each of the posts as a protagonist of the visual content shared. Likewise, it should be highlighted that they did not appear in the company of others in any of the publications with the greatest number of positive interactions.

The followers, through their comments, positively and emphatically interact, showing tokens of affection, support, and solidarity in every publication. Negative comments were not found in most of the contents analyzed, except for specific cases with a positive intention, associated with health and avoiding overweightness (specifically to the user Gabriel Bernardes, given the amount of food normally consumed, according to the posts that are mainly related with baking).

Next, we analyze the posts with the highest number of positive interactions in each of the accounts analyzed, classified according to the type of content shared in their profiles, and starting with the beauty, fashion, and health categories (see Figure 1). Here we find the predominance of colourful photographs with the recurrence of the following hashtags: \#inclusion, \#diversity, \#downsyndrome, \#youarebeautiful, \#differentisbeautiful, \#downsyndromemodel, and \#SDOwnYourBeauty. These posts underline the recognition and exaltation of female beauty of women with Down syndrome. It should be underlined that two of the photographs in Figure 1 show the spontaneity of the influencers, while the rest is showing the photographic production of visual content.

Despite the fact that the influencers in Figure 2 are associated with entrepreneurship and gastronomy, the publications with a higher number of positive interactions were associated with lifestyle, activities, or
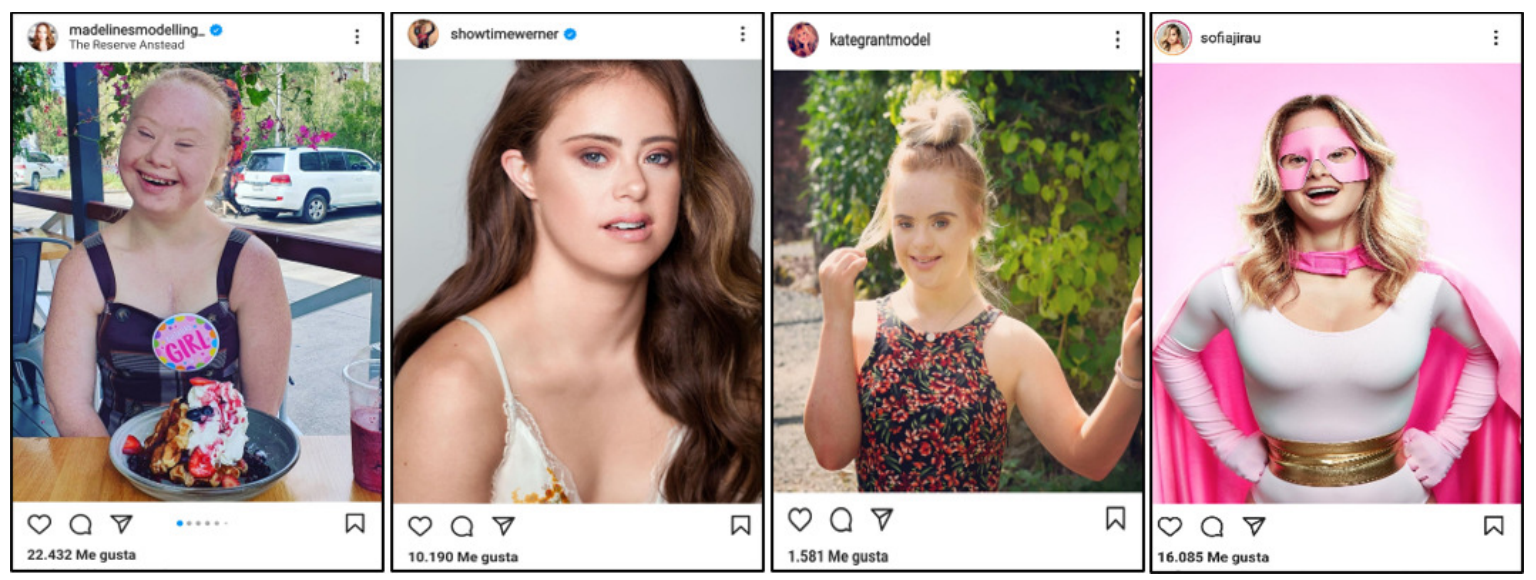

Figure 1. Beauty, fashion, and health categories.

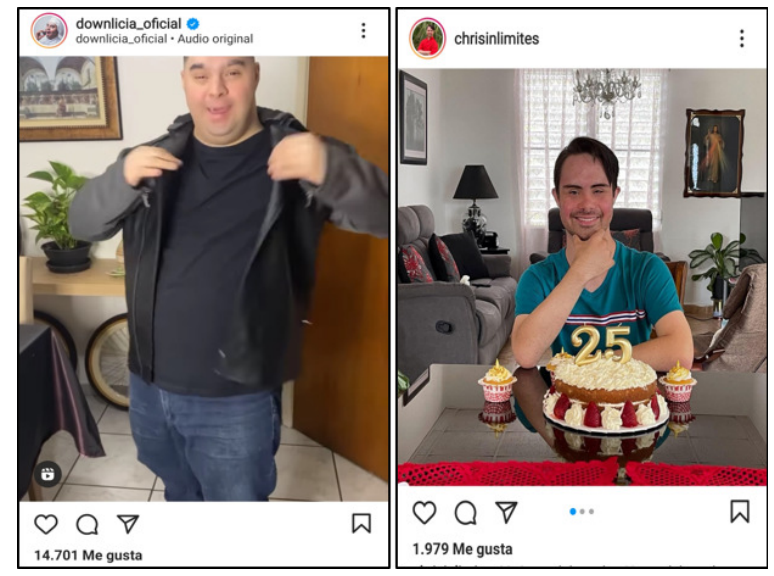

Figure 2. Entrepreneurship and gastronomy categories. 
celebrations in their day-to-day. As for the type of content, the publication from Gabriel Bernardes is a reel, while the one from Christopher González is a photographic carousel. Among the hashtags present in these contents, we found: \#downsyndrome \#cheflife, \#inclusionmatters, \#reels, \#reelsinstagram, \#corleone, \#barberiacorleone, \#dance, and \#sabadou. Both the reels and the carousel rely on a variety of colors, which characterize the posts.

According to the type of post the importance of reels is highlighted, except for the content created by María José Paiz, which is a photographic carousel. All of them share content related to leisure activities and celebrations. Despite all of these influencers in this category (see Figure 3 ) producing content related to their daily life, it is also common for them to directly allude to Down syndrome, except for Patricia Fuentes. In this sense, the most recurring hashtags in these posts were: \#dowsyndrome, \#inclusão, \#empoderamentofeminino, \#diversidade, \#meninassuperpoderosa, \#dance, \#baile, \#moving, \#love, and \#amordown. Likewise, we should highlight a strategy utilized for provoking a response from the audience that is present in all the posts analyzed. That is, the micro-influencers in this category formulate questions in the descriptive text that are directed towards the users to generate interaction with their followers through the comments. Lastly, we should highlight that all the publications used a variety of colors.

\section{Discussion and Conclusions}

SNs provide valuable opportunities to connect with others, forge friendships, find support, and contact groups of peers. SNs can be the first point of contact, beyond the education environment, of people with disabilities with other individuals who have the same characteristics, interests, and needs. They are an opportunity to overcome the population's imagination about Down syndrome and intellectual disability in general as a collective of dependent individuals who need support at the academic, social, and professional levels.
The analysis of the selected influencer profiles in this study shows us individuals who are able to be independent in different areas of professional and social life. The accounts analyzed were managed by microand macro-influencers who have professions as models, cooks, digital creators, or YouTubers, which show their worthiness as verified in the posts analyzed in the present work.

If we delve into the subjects found in the posts, beyond their nature associated with dissemination (fashion, food, digital information, day-to-day aspects, etc.), a generalized interest for showing images, videos, and reels about day-to-day situations was observed. It should be underlined that among the subjects mentioned above, the most representative concerning the presence of sponsors were the contents about fashion, beauty, and health.

As for the nature and spontaneity of the main contents analyzed, these showed a completely normalized image of disability which disappears from the main focus of the posts, becoming an anecdotal aspect, as a personal characteristic without importance.

There is an evident diversity in the accounts; however, the types of posts are recurrent in all the profiles, with photography being prominent. This Instagram carousel dissemination format denoted the increase in the presence of the sponsor as compared to other styles, which resulted in a greater number of positive comments. This, without a doubt, creates a precedent for the planning of future publications for the sake of creating engagement between the followers and influencers or the brands associated with them.

In agreement with Castillo-Abdul et al. (2021), the presence of brands that include support for SNs profiles such as Instagram, as part of their corporate social responsibility, has a positive impact on the image and relationship with groups of interest. This relationship foments positive feedback, and as shown in the results of the present research study, a post that awakens positive emotions as "likes" will perhaps also receive positive comments and vice-versa.
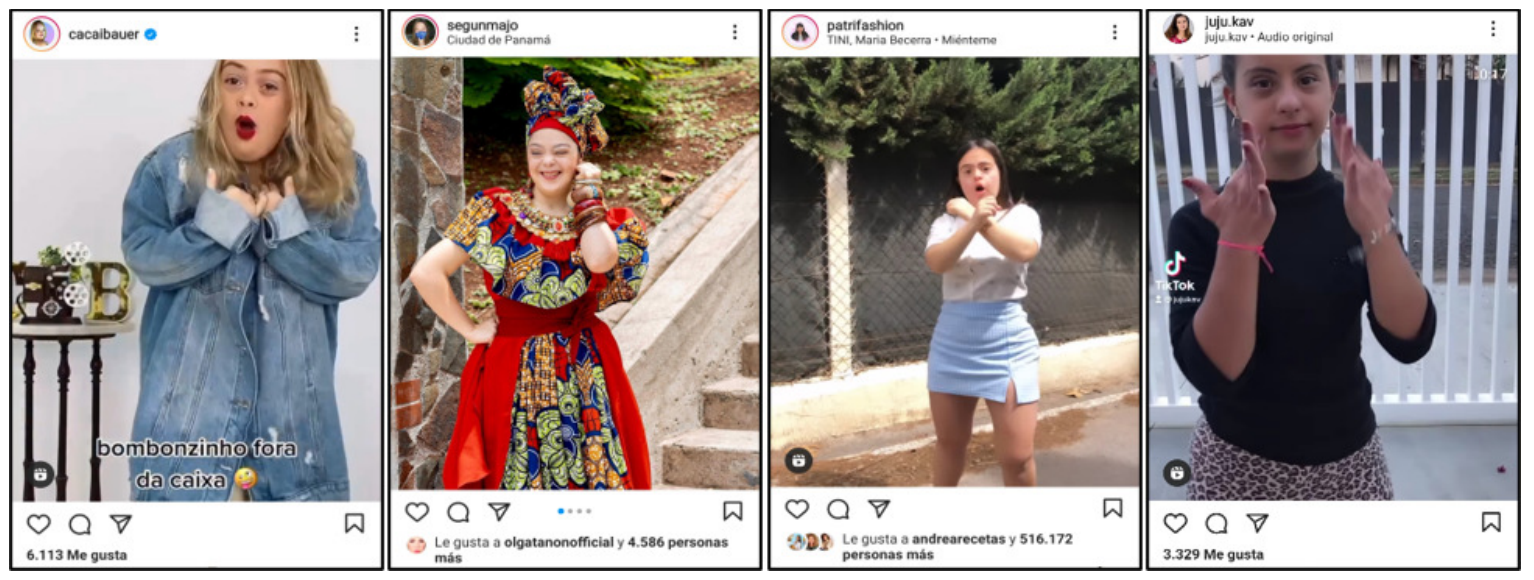

Figure 3. Content creators category. 
A clear intention was evidenced for driving and promoting equality, the achievement of goals, and the personal acceptance and self-realization beyond the limits that are habitually associated with individuals with disabilities. The data obtained highlighted that the accounts analyzed break away from the social image present in the collective ideology. The accounts analyzed showed that we can overcome this strongly stereotyped, sensationalist, un-personalized view, which presents the people with disabilities as a homogenous collective (Ledesma, 2008; Vidal-García, 2021; Viñarás-Abad et al., 2021), thanks to publications of young people such as those analyzed in the present work.

Among the limitations, we find, in the first place, the construction of the variable "positive interactions," which combines the number of likes with the number of positive comments, given that they are not two equivalent categories - the proportion of comments is much lower than the likes; they are, therefore, more "valuable." At the same time, in the video or IGTV posts, the likes are not counted, so this variable was not calculated. Nevertheless, we independently measured the likes, comments, and in the case of the videos and IGTV, views, which showed a high correlation between them and with the volume of positive interactions. As such, this variable was kept in an exploratory manner, although we must be cautious when reporting these data. On the other hand, it is possible that the reduced number of accounts analyzed could have limited the observations so that these are not statistically significant; this is particularly true in the case of the theme, as less than half of the cases could be clearly and unambiguously classified into a category that allowed their quantitative analysis. Likewise, another limitation of the study is the terminological designations utilized, as the concept of "disability," although internationally accepted, has diverse connotations according to the national context in each country. Thus, it is also important to delve into the language utilized because the use of one type of language over another leads to different manners of thinking, feeling, and acting, and therefore, of social awareness. With respect to this, SNs also have a great impact, especially in light of the recognition of sensitive collectives such as the one studied.

In future studies, it would be necessary to delve into these aspects with larger samples; nevertheless, the present article serves as an initial exploratory analysis, combining quantitative data with a deeper qualitative analysis. Also, the data obtained can serve for the reflection and actions that could be included in training materials for teachers and communication professionals, who can become aware of the importance and impact that SNs can have in their respective fields. For this, the present study, and the larger project within which it is framed, allow us to reflect on the involvement that SNs could have for being elements that facilitate the process of inclusion, and that without a doubt play a determinant role. In the words by Marchesi (2019), it is about pro- moting an inclusive process that requires three bridges: a political bridge to adopt policies and budgets oriented towards this aim; a sociocultural bridge, which tries to create favorable citizen attitudes towards inclusion; and lastly, an educational bridge that involves attention to diversity as a key axis of the system, and teacher training. However, we must also add a fourth bridge, communication and digitalization, which implies addressing the impact of SNs on the public sphere as they create attitudes, favoring different opinions and promoting awareness and sensitivity towards differences and diversity. It is also about dealing with a re-thinking of the initial and permanent training of education professionals, communication, and social intervention, to address the legal and ethical professional responsibilities towards the construction of a more just, equal, and inclusive context.

Along the way, digital competence training is a fundamental aspect. For this, in the socio-educational sphere, the UDL (Centre for Assistive Special Technologies, 2013) is revealed as a theoretical-practical approach that allows for the development of profound inclusive socio-educational proposals. The UDL was developed by the Centre for Assistive Special Technologies (2013) and is founded on advances in neurosciences, learning theories, the results from educational practices and research, and the fundamental contributions from technology (Meyer et al., 2016). Scientific evidence backs the reach of UDL, as it increases the access and participation of all the students, improves academic results and social participation, as indicated by the results from the research by Wook-Ok et al. (2017), Capp (2017, 2020), and Rodríguez-Martín et al. (2020). Likewise, the social fabric has an unprecedented opportunity for creating new relationships, and increasing the reach and visibility, which could be harnessed to improve the quality of life conditions of individuals with intellectual disabilities, and, at the same time, to continue to assert their rights and equality of opportunities.

Thus, we can conclude that Instagram is not only a tool that is able to provide visibility to individuals with intellectual disabilities but is also able to change the collective imagination concerning people with Down syndrome. All of this is a turning point for achieving social and work inclusion of this collective and to provide evidence of the positive impact that SNs could have in their personal, educational, and community spheres.

\section{Acknowledgments}

This work was conducted within the framework of Alfamed (Euro-American Network of Researchers), with the support of the R+D Project Youtubers and Instagrammers: Media Competence in Emerging Prosumers (RTI2018-093303-B-I00), financed by the State Research Agency of the Spanish Ministry of Science, Innovation and Universities and the European Regional Development Fund. 


\section{Conflict of Interests}

The authors declare no conflict of interests.

\section{References}

Alassani, R., \& Göretz, J. (2019). Product placements by micro and macro influencers on Instagram. In G. Meiselwitz (Ed.), Social computing and social media: Communication and social communities (pp. 251-267). Springer. https://doi.org/10.1007/978-3030-21905-5_20

Alfredsson, K., Kjellberg, A., \& Hemmingsson, $H$. (2019). Digital participation? Internet use among adolescents with and without intellectual disabilities: A comparative study. New Media \& Society, 22(12), 2128-2145. https://doi.org/10.1177/1461 444819888398

Augure. (2015). Estatus y prácticas de las relaciones con influencers en 2015 [Status and practices of the relationships with influencers in 2015]. https://bit.ly/ 3d0luoe

Bayor, A., Bircanin, F., Sitbon, L., Ploderer, B., koplick, S., \& Brereton, M. (2018). Characterizing participation across social media sites amongst young adults with intellectual disability. In $\mathrm{OzCHI}$ '18: Proceedings of the 30th Australian conference on computer-human interaction (pp. 113-122). Association for Computing Machinery. https://doi.org/ 10.1145/3292147.3292167

Birnholtz, J., \& Macapagal, K. (2021). “I don't want to be known for that": The role of temporality in online self-presentation of young gay and bisexual males. Computers in Human Behavior, 118, Article 106706. https://doi.org/10.1016/j.chb.2021.106706

Booth, T., \& Ainscow, M. (2015). Index for inclusion: Developing learning and participation in schools. CSIE.

Borgström, A., Daneback, K., \& Molin, M. (2019). Young people with intellectual disabilities and social media: A literature review and thematic analysis. Scandinavian Journal of Disability Research, 21(1), 129-140. http://doi.org/10.16993/sjdr.549

Caldeira, S. P. (2021). "It's not just Instagram models:" Exploring the gendered political potential of young women's Instagram use. Media and Communication, 9(2), 5-15. https://doi.org/10.17645/mac.v9i2.3731

Capp, M. J. (2017). The effectiveness of universal design for learning: A meta-analysis of literature between 2013 and 2016. International Journal of Inclusive Education, 21, 791-807. https://doi.org/10.1080/ 13603116.2017.1325074

Capp, M. J. (2020). Teacher confidence to implement the principles, guidelines, and checkpoints of universal design for learning. International Journal of Inclusive Education, 24, 706-720. https://doi.org/ 10.1080/13603116.2018.1482014

Carbonell, G. J. (2019). The independent living move- ment in Spain. Spanish Journal of Disability, 7, 201-214. https://doi.org/10.5569/2340-5104.07.02. 12

Castelló-Martínez, A. (2016). El marketing de influencia: Un caso práctico [The influence marketing: A practical case]. In I. Zacipa-Infante, V. Tur-Viñes, \& J. Segarra-Saavedra (Eds.), Tendencias publicitarias en Iberoamérica: Diálogo de saberes y experiencias [Advertising trends in Ibero-America: Dialogue of knowledges and experiences] (pp. 49-65). Colección Mundo Digital. https://doi.org/10.14198/MEDCOM/ 2016/8

Castillo-Abdul, B., Pérez-Escoda, A., \& Civila, S. (2021). Social media fostering happiness management: Three luxury brands case study on Instagram. Corporate Governance. Advance online publication. https://doi.org/10.1108/CG-05-2021-0201

Caton, S., \& Chapman, M. (2016). The use of social media and people with intellectual disability: A systematic review and thematic analysis. Journal of Intellectual \& Developmental Disability, 41(2), 125-139. https:// doi.org/10.3109/13668250.2016.1153052

Centre for Assistive Special Technologies. (2013). Pautas sobre el diseño universal para el aprendizaje (DUA) [Universal design for learning guidelines]. https://bit. Iy/2BUtKLy

Chadwick, D. D., Quinn, S., \& Fullwood, C. (2016). Perceptions of the risk and benefits of internet access and use by people with intellectual disabilities. British Journal of Learning Disabilities, 45(1), 21-31. https:// doi.org/10.1111/bld.12170

Chaves, A. (2020, September 3). El carrusel es el formato de Instagram con más engagement: Por qué deberías usarlo. [Photo dump is the most engaging Instagram format: Why your should use it]. Marketing 4 Ecommerce. https://bit.ly/3h4rUtt

Chiner, E., Gómez-Puerta, M., \& Cardona-Moltó, C. (2017). Internet use, risk and online behaviour: The view of internet users with intellectual disabilities and their caregivers. British Journal of Learning Disabilities, 45(3), 190-197. https://doi.org/10.1111/ bld.12192

del-Pino-Romero, C., \& Castelló-Martínez, A. (2017). La estrategia publicitaria basada en influencers. El caso de SmartGirl by Samsung [Advertising strategy based on influencers. The case of SmartGirl by Samsung]. In A. Castelló-Martínez \& C. del-Pino-Romero (Eds.), Publicidad y convergencia mediática. Nuevas estrategias de comunicación persuasiva [Advertising and literacy convergence. New strategies of persuasive communication] (pp. 116-146). Egregius Ediciones.

Goffman, E. (1959). The presentation of self in everyday life. Doubleday. https://bit.ly/31RIhRW

González-Romo, Z. F., \& Iriarte-Aguirre, S. (2020). Análisis de la gestión de la comunicación de los influencers farmacéuticos españoles en Instagram durante la pandemia del Covid-19 [Analysis of the management of the communication of Spanish pharmaceutical 
influencers in Instagram during the Covid-19 pandemic]. Revista Española de Comunicación en Salud, 2020(1), 9-30. https://doi.org/10.20318/recs.2020. 5402

Goodall, C. (2020). Inclusion is a feeling, not a place: A qualitative study exploring autistic young people's conceptualisations of inclusion. International Journal of Inclusive Education, 24, 1285-1310. https://doi. org/10.1080/13603116.2018.1523475

Kemp, S. (2020). Digital in 2020. We Are Social; Hootsuite. https://bit.ly/3gLAqfF

Kim, K. M., \& Quian, X. (2019). "I feel valued": The experience of social networking site engagement among people with intellectual and developmental disabilities in South Korea. International Journal of Developmental Disabilities, 67(6), 410-419. https://doi.org/ 10.1080/20473869.2019.1670007

Ledesma, J. A. (2008). La imagen social de las personas con discapacidad [The social image of people with disabilities]. CERMI.

Marchesi, A. (2019). Salamanca 1994-2019: There is still a long way to Latin America. International Journal of Inclusive Education, 23(7/8), 841-848. https://doi. org/10.1080/13603116.2019.1622803

Marketing Directo. (2020). Influenciadores: Diccionario de marketing directo e interactivo [Influencers: Dictionary of direct and interactive marketing]. https:// bit.ly/3jFSCKD

McRoberts, S., Bonsignore, E., Peyton, T., \& Yarosh, S. (2016). Do it for the viewers! Audience engagement behaviors of young YouTubers. In Proceedings of the 15th international conference on interaction design and children (pp. 334-343). Association for Computing Machinery. https://doi.org/10.1145/ 2930674.2930676

Meyer, A., Rose, D. H., \& Gordon, D. (2016). Universal design for learning: Theory and practice. CAST Professional Publishing.

Pérez-Torres, V., Pastor-Ruiz, Y., \& Abarrou-BenBoubaker, S. (2018). Los youtubers y la construcción de la identidad adolescente [YouTuber videos and the construction of adolescent identity]. Comunicar, 55, 61-70. https://doi.org/10.3916/C55-2018-06

Raghavendra, P., Newman, L., Grace, E., \& Wood, D. (2015). Enhancing social participation in young people with communication disabilities living in rural Australia: Outcomes of a home-based intervention for using social media. Disability and Rehabilitation, 37(17), 1576-1590. https://doi.org/10.3109/ 09638288.2015 .1052578

Ramstem, C., Martín, L., Dag, M., \& Hammar, L. M. (2018). Information and communication technology use in daily life among young adults with mildto-moderate intellectual disability. Journal of Intellectual Disabilites, 24(3), 289-308. https://doi.org/ 10.1177/1744629518784351

Rodríguez-Martín, A., Alvarez-Arregui, E., \& OrdialesIglesias, T. (2020). Huellas para la inclusión: Funda- mentos para responder a la diversidad e implementar el Diseño Universal para el Aprendizaje [Trace for the inclusion: Foundations for responding to diversity and implementing the Universal Design for Learning]. Ediuno.

Román, P., \& Rodríguez-Martín, A. (2019). Students with intellectual disabilities: Access to information, communication and knowledge. In J. M. Batanero (Ed.), Teacher training for the incorporation of ICT in students with functional diversity (pp. 93-109). Octaedro.

Romero-Coves, A., Carratalá-Martínez, D., \& SegarraSaavedra, J. (2020). Influencers y moda en redes sociales. Análisis de las principales modelos españolas en Instagram [Influencers and fashion in social networks. Analysis of the principal Spanish models in Instagram]. Redmarka: Revista de Marketing Aplicado, 24(2), 44-58. https://doi.org/10.17979/redma. 2020.24.2.7053

Sallafranque-St-Louis, F., \& Normand, C. L. (2017). From solitude to solicitation: How people with intellectual disability or autism spectrum disorder use the internet. Cyberpsychology: Journal of Psychosocial Research on Cyberspace, 11(1), Article 7. https://doi. org/10.5817/CP2017-1-7

Saz-Torralba, O., Rodríguez-Dueñas, W. R., \& LleidaSolano, E. (2011). Development of voice-based tools for accessibility to computer services. Computación y Sistemas, 15(1), 7-15. https://bit.ly/35uXnP3

Setchell, J., Barlott, T., \& Torres, M. (2020). A socialemotional analysis of technology use by people with intellectual disabilities. Journal of Intellectual Disability Research, 65(2), 149-161. https://doi.org/ 10.1111/jir.12796

Shume, T. J. (2020). Conceptualising disability. International Journal of Inclusive Education. Advance online publication. https://doi.org/10.1080/13603116. 2020.1839796

Smith, A. N., Fischer, E., \& Yongjian, C. (2012). How does brand-related user-generated content differ across YouTube, Facebook, and Twitter? Journal of Interactive Marketing, 26(2), 102-113. https://doi.org/ 10.1016/j.intmar.2012.01.002

Suriá, R. (2017). Redes virtuales y apoyo social percibido en usuarios con discapacidad: Análisis según la tipología, grado y etapa en la que se adquiere la discapacidad [Virtual networks and perceived social support in users whit disability: Analysis to the type, grade and stage in which the disability is acquired]. Escritos de Psicología, 10(1), 31-40. https://doi.org/ 10.5231/psy.writ.2017.21403

Tollan, K. (2020). Exploring the development of identity and community amongst disabled youth on Instagram [Doctoral dissertation, Brock University]. Brock University Digital Repository. https://bit.ly/ 3cw1EW5

Tsatsou, P. (2019). Digital inclusion of people with disabilities: A qualitative study of intra-disability diversity 
in the digital realm. Behaviour \& Information Technology, 39(9), 995-1010. https://doi.org/10.1080/ 0144929X.2019.1636136

Tsatsou, P. (2020). Is digital inclusion fighting disability stigma? Opportunities, barriers, and recommendations. Disability \& Society, 36(5), 702-729. https:// doi.org/10.1080/09687599.2020.1749563

UNESCO. (2015a). World education forum 2015: Final report. https://bit.ly/3DIfocp

UNESCO. (2015b). Global monitoring report on education. https://bit.ly/3tfnXXa

UNESCO. (2015c). Incheon declaration and framework for action for the implementation of sustainable development goal 4. https://bit.ly/3h2Dkxn

United Nations. (2006). Convention on the rights of persons with disabilities. https://bit.ly/2WKNpZ9

Vidal-García, J. (2021). Los derechos de las personas con discapacidad "Un espejo donde mirarse, en la prensa digital española" [The rights of people with disabilities "A mirror to look at, in the Spanish digital press"]. Paideia XXI, 11(1), 43-61. https://doi.org/10.31381/ paideia\%20xxi.v11i1.3734

Villena-Alarcón, E., \& Fernández-Torres, M. J. (2020). Relaciones con los públicos a través de Instagram: Los influencers de belleza como caso de estudio [Beauty on Instagram: Relations between influencers and the stakeholders]. Revista Internacional de Relaciones Públicas, 10(19), 111-132. http://doi.org/ 10.5783/RIRP-19-2020-07-111-132

Viñarás-Abad, M., Vázquez-Barrio, T., \& Sánchez-Valle, M.
(2021). Situación de las personas con discapacidad en el sector de la comunicación en España: Aspectos laborales, profesionales y académicos [Situation of people with disabilities in the communication sector in Spain: Labor, profesional and academic aspects]. Profesional de la Información, 30(2), 1-15. https:// doi.org/10.3145/epi.2021.mar.02

Vissenberg, H., \& d'Haenens, L. (2020). Protecting youths' wellbeing online: Studying the associations between opportunities, risks and resilience. Media and Communication, 8(2), 175-184. https://doi.org/ 10.17645/mac.v8i2.2774

Werner, S., \& Shpigelman, C. N. (2019). Information and communication technologies: Where are persons with intellectual disabilities? Israel Journal of Health Policy Research, 8(6), Article 6. https://doi. org/10.1186/s13584-018-0282-4

White, P., \& Forrester-Jones, R. (2019). Valuing einclusion: Social media and the social networks of adolescents with intellectual disability. Journal of Intellectual Disabilities, 24(3), 381-397. https://doi. org/10.1177\%2F1744629518821240

Wook-Ok, M., Rao, K., Bryant, B. R., \& McDougall, D. (2017). Universal design for learning in pre-k to grade 12 classrooms. Exceptionality, 25, 116-138. https:// doi.org/10.1080/09362835.2016.1196450

World Health Organization. (2001). The international classification functioning, disability and health. https://bit.ly/3n4yC66

\section{About the Authors}
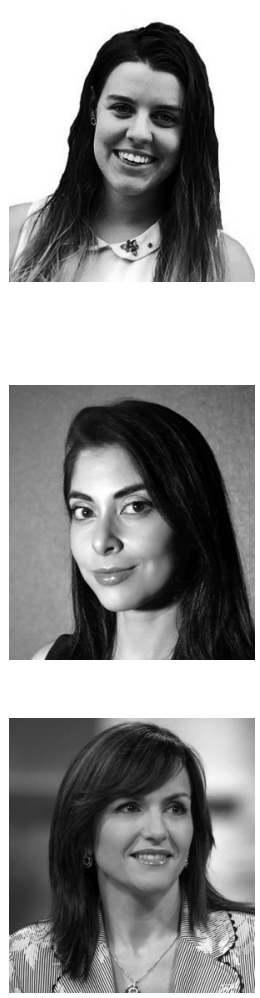

Mónica Bonilla-del-Río is a predoctoral researcher at the Department of Philology of University of Huelva, contracted under the University Teacher Training Programme, financed by Spanish Ministry of Education, Culture and Sports (MECD). She is a PhD student in the Interuniversity Program in Communication at the Universities of Seville, Malaga, Huelva, and Cadiz. She has a MA in Communication and Audiovisual Education at the International University of Andalusia and the University of Huelva. She is vice-president of Alfamed young (Euro-American Inter-University Network for Research on Media Literacy for Citizenship) and she is a member of the research group HUM-648 Ágora. https://orcid.org/0000-0003-2476-8922

Bárbara Castillo-Abdul is a predoctoral researcher at the Department of Communication Sciences and Sociology of Rey Juan Carlos University (Spain) and visiting professor at ESAI Business School, Universidad Espíritu Santo in Ecuador. Student of the PhD program in communication at the University of Huelva and the Social and Legal Sciences program at Rey Juan Carlos University. She is a member of the European Communication Research and Education Association, International Association for Media and Communication Research, Euro-American Inter-University Network for Research on Media Literacy for Citizenship. https://orcid.org/0000-0002-3711-1519

Rosa García-Ruiz has a PhD in educational sciences from the National University of Distance Education. She is a professor at the Universidad de Cantabria (Spain) and director of the Department of Education. Collaborator of Nebrija Univesity (Spain), she is also assistant editor of Comunicar journal (JCR \& Scopus Q1). Her lines of research are educational innovation and digital and media literacy. She participates in competitive national and international research projects. She is a member of Alfamed (Euro-American Inter-University Network for Research on Media Literacy for Citizenship). https://orcid.org/0000-0003-1445-6968 


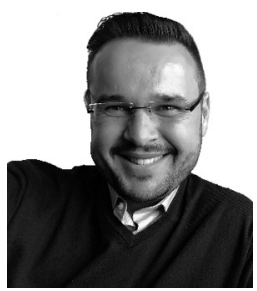

Alejandro Rodríguez-Martín has a PhD in educational sciences from University of Las Palmas de Gran Canaria (Spain). He is a professor at University of Oviedo (Spain) and director of the Department of Education Sciences. He has also been a visiting researcher at different higher education institutions and research centers in Europe and America. His lines of research are inclusive education, entrepreneurial training ecosystems and digital mentoring, and active ageing and digital inclusion. He is a member of the Spanish Society of Pedagogy, Inclusive University Network, European Network of Inclusive Education and Disability Included, Transdisciplinary Educational Research Network, and Alfamed. https://orcid.org/0000-0002-4230-4243 